\title{
First imported Plasmodium ovale malaria in Central America: case report of a Guatemalan soldier and a call to improve its accurate diagnosis
}

\author{
María Eugenia Castellanos ${ }^{1}$, Sheilee Díaz ${ }^{2}$, Emily Parsons ${ }^{3}$, Leonard F Peruski ${ }^{4}$, Fabiola Enríquez ${ }^{5}$, \\ Juan Luis Ramírez ${ }^{6}$ and Norma Padilla ${ }^{1 *}$
}

\begin{abstract}
The Mesoamerican Ministers of Health have set 2020 as the target for malaria elimination to be achieved in the region. Imported malaria cases are a potential threat to countries attempting elimination or working to prevent resurgence. We report the first imported Plasmodium ovale infection with molecular confirmation in Central America, which occurred in a Guatemalan soldier that had been deployed in Africa. The obstacles for its diagnosis using the standard microscopy technique and the need to improve its detection are discussed.
\end{abstract}

Keywords: Plasmodium ovale, Imported malaria, Diagnosis

\section{Background}

One factor in the worldwide increase of imported malaria cases has been the presence of armed forces and United Nations (UN) peacekeeping missions in malariaendemic areas and their subsequent return to their countries of origin [1]. As expected, the majority of the cases are caused by Plasmodium falciparum or P. vivax. However, P.ovale infection has been established as a relevant cause of imported malaria in these groups, resulting in challenges for accurate diagnosis and treatment [2].

$P$. ovale is mainly distributed in sub-Saharian Africa and the islands of western Pacific with prevalence between $3-10 \%$ depending on the region, population and type of diagnostic tests used [3,4]. Recently, Sutherland et al. demonstrated there are two non-recombining sympatric species of $P$. ovale, named P. ovale curtisi (classic type) and $P$. ovale (variant type) [5]. In Latin America, no autochthonous $P$. ovale cases have occurred and there have been just a few reports of imported $P$. ovale infections [6-8].

\footnotetext{
* Correspondence: npadilla@ces.uvg.edu.gt

${ }^{1}$ Center for Health Studies-Universidad del Valle de Guatemala (CES-UVG), 18 Av. 11-95 zona 15, Vista Hermosa III, Guatemala City, CA, Guatemala Full list of author information is available at the end of the article
}

Guatemala is a Central American country, with approximately $80 \%$ of its territory considered a malaria transmission setting [9]. P. vivax and P. falciparum are the etiologic agents of malaria, with the last case of $P$. malariae reported in 1971 and no $P$. ovale cases ever documented in Guatemala [10]. In the last decade, and largely based on the scale up of vector-control strategies, a significant reduction in the number of malaria cases in the country had been observed, from 39,703 cases in 2005 [11] to 3,292 cases in 2013 (Guatemalan Malaria Control Program, unpublished data). The same trend has been observed in all Mesoamerican countries and the Española Islands (Dominican Republic and Haiti) (Malaria Control Programs, unpublished data). Thus, malaria programs in Guatemala and Mesoamerica are now aiming towards malaria elimination rather than only prevention and control. However, imported cases pose a threat to this goal [12].

Since 2004, Guatemala has deployed military personnel to contribute to UN peacekeeping missions. In 2010, an epidemiological investigation detected 12 cases of imported $P$. falciparum malaria in 150 Guatemalan soldiers returning from the Democratic Republic of the Congo (DRC) $[13,14]$. Since this event, molecular screenings to detect $P$. vivax /P. falciparum malaria carriers are 
conducted annually among returning contingents from the DRC as part of a program established between the Guatemalan National Reference Laboratory, Universidad del Valle de Guatemala and Military Healthcare and Social Services. Here we present the first $P$. ovale case detected in this population. To the best of our knowledge this is the first report of molecularly-confirmed imported P. ovale infection in Central America. The challenges that this case presented for an accurate diagnosis and the need to incorporate more sensitive methods will be discussed.

\section{Case presentation}

A 38-year-old male Guatemalan soldier presented to the facilities of the Military Hospital on June 29, 2012, to confirm suspected $P$. vivax malaria. Three months previously he had returned from a 9-month deployment in Africa, as part of a Guatemalan Army operation to aid the UN Organization Stabilization Mission in DRC.

The soldier reported that during his time in DRC he stayed in the towns of Dungu, Bangadi and Bunia. He travelled for a short period of time to Entebbe and Kampala (Uganda) and Mombasa (Kenya) as part of his rest and recuperation time. During the entire mission, he used an untreated bed net and received mefloquine prophylaxis (250 mg base/week). He reported high compliance with the drug, although he admitted to skipping some doses during his period in Uganda and Kenya. Upon his return to Guatemala, he and all deployed personnel were screened by malaria microscopy and P.vivax/P.falciparum PCR. Microscopic and molecular results were negative for the entire contingent.

Two months after his return to Guatemala, the patient travelled to Puerto de San José, Escuintla (a coastal zone in the southern Guatemala) and then returned to his residence in Jalpatagua, Jutiapa (eastern region). Malaria is endemic in both of these regions. He reported fatigue and fever, and malaria was clinically diagnosed by a private physician without any laboratory confirmation. $\mathrm{He}$ was given chloroquine diphosphate injections (no available dosage data) because the standard treatment in $P$. falciparum/P. vivax (the two endemic malaria parasites of the country) includes chloroquine [15].

The patient reported an improvement and returned to military duties. Three weeks later, he again presented with fever and fatigue. Malaria microscopy conducted at the Jutiapa Malaria Vector Control Program erroneously diagnosed a $P$. vivax infection. The patient was transferred to Guatemala City to be evaluated in the Military Medical Center.

Venous and capillary blood was taken for laboratory testing. A thin blood film identified $P$. vivax, although concerns about the morphology of some of the observed parasites were raised by the hospital microbiologist. A complete blood count at admission revealed thrombocytopenia (71,000 platelets/ $\mu \mathrm{l})$ and anemia (haemoglobin $12 \mathrm{~g} / \mathrm{dl})$. A rapid dengue diagnostic assay showed a current or recent infection. Other laboratory tests results were within reference values.

Based on the travel history of the patient and the doubts arisen as to its species identity, molecular testing was conducted to confirm the Plasmodium species. A $P$. ovale mono-infection was identified on both the blood film and whole blood of the patient using a Plasmodium genus-specific nested PCR (Figure 1) and a SYBR Greenbased quantitative real-time PCR $[16,17]$. The blood film was re-examined to identify the morphological features of

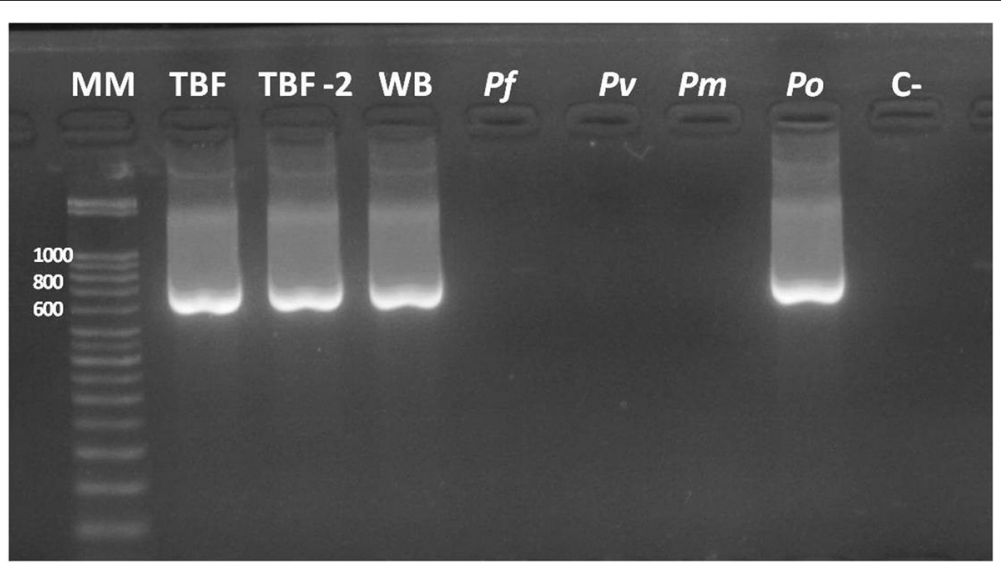

Figure 1 Molecular detection of Plasmodium ovale in blood samples from patient by the amplification of $18 \mathrm{~S}$ gene. Nested PCR with Plasmodium genus-conserved primers was followed by $P$. ovale specific primers. PCR products were separated by electrophoresis through a 2.0\% agarose gel stained with ethidium bromide and flanked by a 50 bp DNA ladder (Novagen) as a size marker. Lane MM: Molecular marker 50 bp. Lane TBF: Patient's thin blood film. LaneTBF-2: Patient's thin blood film (duplicate). Lane WB: Patient's whole blood. Lane Pf: Plasmodium falciparum control. Lane Pv: Plasmodium vivax control. Lane Pm: Plasmodium malariae control. Lane Po: Plasmodium ovale positive control. Lane C-: Negative control. 
this parasite (Figure 2). Sequence analysis was conducted to discriminate between the classic or variant $P$. ovale. Basic local alignment search tool (BLAST) analysis revealed 95\% similarity with $P$. ovale ssrRNA gene. The strain was classified as the classic type, $P$. ovale curtisi, based on its nucleotide polymorphisms [5]. The Genetics and Immunology Laboratory, Malaria Branch at Centers for Disease Control (Atlanta, US) confirmed these findings.

For malaria treatment he was prescribed $1,500 \mathrm{mg}$ of chloroquine base given over 3 days and $15 \mathrm{mg}$ of primaquine base over 14 days, following national guidelines for the treatment of $P$. vivax infections, as the results of the molecular analyses were not available at the time of treatment initiation. The patient was discharged after his clinical condition and hematological results improved. Follow up specimens were taken at day 1, one and two months after treatment completion, confirming parasite clearance. Also, all family members in the household and one neighbor provided blood samples, with negative results for Plasmodium spp. As a control measure, the household was sprayed with deltamethrin.

Here we present the first imported Plasmodium ovale case in Guatemala. Based on the patient's travel history, he could have acquired the infection in any of the African countries he stayed in, as $P$. ovale is present in all of them $[3,18]$. Lack of strict compliance with both chemoprophylaxis and personal protective measures has been cited as a cause of imported malaria in deployed military personnel
[19]. The patient's late onset of symptoms corresponds to previous observations that anti-malarial prophylaxis delays, but does not prevent, the primary attack [3].

This report highlights the need to consider $P$. ovale as a cause of imported malaria and to include its detection, as well as P. malariae, in imported malaria screening programs. This patient presented particular diagnostic challenges that resulted in a failure of early detection and diagnosis of $P$. ovale infection. Distinguishing $P$. ovale from $P$. vivax by microscopy, already difficult due to the species' morphologic similarity [20], was further confounded in this case by $P$. ovale's non-indigenous status. Since this event, all returning military contingents are being tested with a pan-Plasmodium real time PCR assay. In addition to malaria screening programs, clinical diagnoses should not automatically exclude consideration of non-endemic species of malaria. Regular training of microscopists for the accurate identification of all malaria parasites, including non-indigenous species, should be mandatory [21].

In addition to mitigating the diagnostic challenges of imported malaria, monitoring imported cases into an already malaria-endemic area is important because the presence of viable vectors could lead to secondary autochthonous cases and the spread of drug-resistant strains, thus hampering malaria control and elimination efforts in regions, such as Central America that remains one of the few areas of the world where no antimalarial drug resistance has been reported [22]. An observed change in the

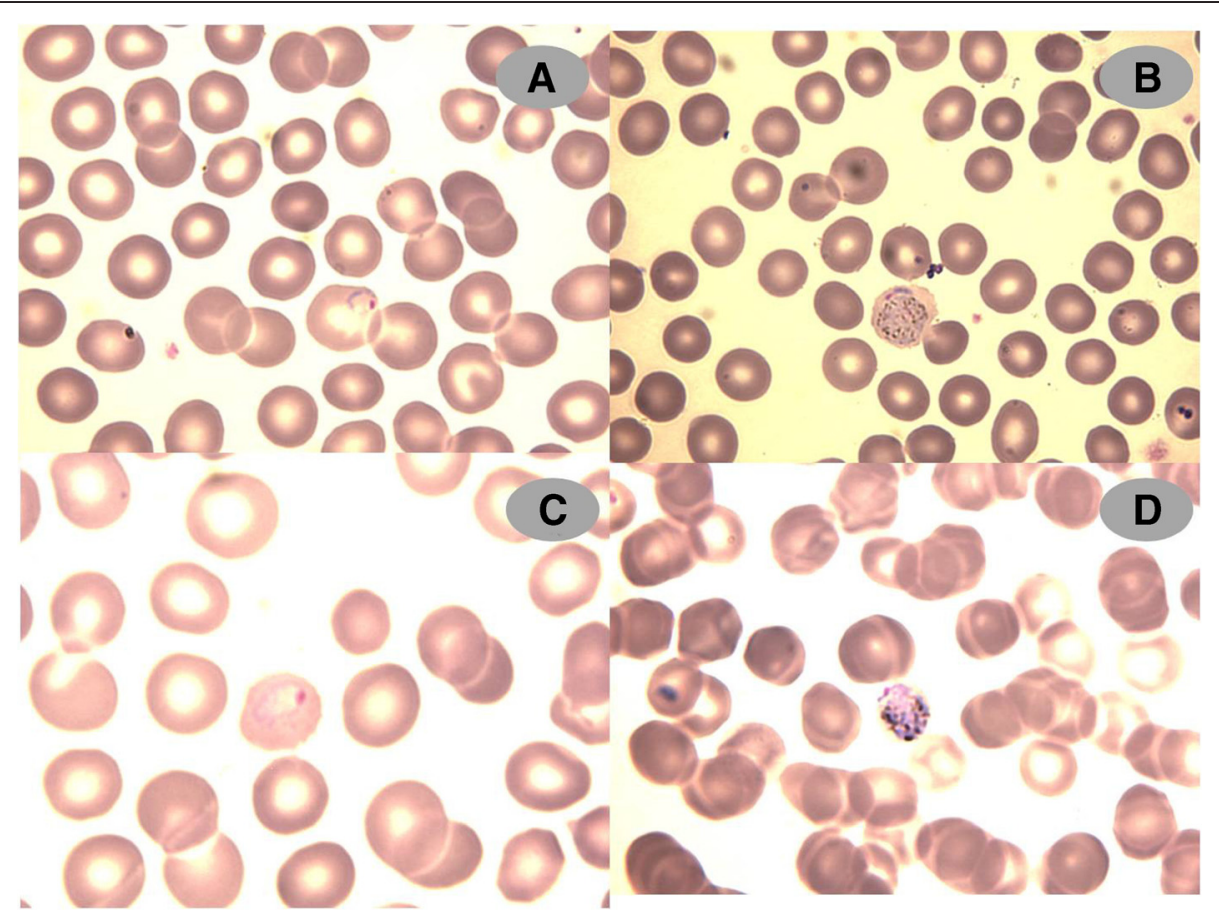

Figure 2 Plasmodium ovale parasites (initially diagnosed as $P$. vivax) shown in different stages in the blood smear of the patient at time of presentation (Giemsa Stain, X 1000). A and C: ring-form trophozoites. B and D: gametocytes. 
number of imported cases or species of malaria could help re-direct prevention efforts both internationally and within Guatemala. Moreover, the combined use of molecular methods and microscopy will have the added benefit of possibly increasing detection of asymptomatic infections [23], allowing us to determine the true burden of infection and potential interactions among Plasmodium species [4].

Considering the long latency of these infections, further strategies should be considered to improve prevention. For instance, the use of presumptive anti-relapse therapy could be an effective approach to prevent relapses of $P$. vivax or $P$. ovale infections in long-term Army deployments which are significantly exposed to these parasites [24].

\section{Conclusions}

Imported malaria cases could lead to the introduction of drug resistant strains in Central America, as well as atypical malaria species, especially in areas where competent hosts could harbor these parasites and transmit them [3]. An integrated and timely malaria surveillance system is warranted in order to rapidly detect and control the emergence of these imported infections in the country. In the era of malaria elimination, improved guidelines for the diagnosis, treatment and control of imported malaria cases are crucial in Mesoamerica to mitigate the risk posed by such novel cases of imported infections.

\section{Consent}

Written informed consent was obtained from the patient for publication of this Case Report. A copy of the written consent is available for review by the Editor-in-Chief of this journal.

\section{Competing interests}

The authors declared that they have no competing interests.

\section{Authors' contributions}

All authors have made substantial contributions to the investigations presented in this manuscript. MEC drafted the manuscript. SD, FE participated in clinical and epidemiological data collection. MEC, EP, LP and $J$ LR carried out the laboratory and molecular studies. NP conceived and designed the case report. All authors have read and approved the final manuscript.

\footnotetext{
Acknowledgments

We want to thank the patient for his consent and enthusiastic participation in this report. Also, many thanks to Kim Lindblade for revising the manuscript and to Venkatachalam Udhayakumar and Naomi Lucchi for confirming the molecular results. We also thank Ranfery Trampe for his contribution in the epidemiological data collection in Jutiapa, Lucía Ortiz for help in the bioinformatic analyses and Bernarda Molina for the microscopy diagnosis and photography. Finally, we appreciate the diagnostic assistance of the DPDx Team from the CDC's Division of Parasitic Diseases and Malaria for the identification of the blood stages of the parasite.
}

\section{Author details}

${ }^{1}$ Center for Health Studies-Universidad del Valle de Guatemala (CES-UVG), 18 Av. 11-95 zona 15, Vista Hermosa III, Guatemala City, CA, Guatemala. ${ }^{2}$ National Reference Laboratory, Ministry of Health and Welfare, Km. 22, Carretera al Pacífico, Barcenas, Villa Nueva, CA, Guatemala. ${ }^{3}$ F. Edward Hebert School of Medicine, Uniformed Services, University of the Health Sciences, 4301 Jones Bridge Road, 20814 Bethesda, MD, USA. ${ }^{4}$ Global Disease Detection Program, Centers for Disease Control and Prevention (CDC), Central America Regional Office, 1600 Clifton Road NE, MS-D68, 30333 Atlanta, GA, USA. ${ }^{5}$ Military Healthcare and Social Services, Ministry of Defense, Guatemala. Finca El Palomar, Acatan, Sta. Rosita Zona 16, Guatemala City, Guatemala. ${ }^{6}$ Military Medical Center, Ministry of Defense, Guatemala. Finca El Palomar, Acatan, Sta. Rosita Zona 16, Guatemala City, Guatemala.

Received: 15 July 2014 Accepted: 5 January 2015

Published online: 15 February 2015

\section{References}

1. World Health Organization. World malaria report 2011. Geneva: World Health Organization; 2011.

2. de Laval F, Oliver M, Rapp C, Pommier de Santi V, Mendibil A, Deparis X, et al. The challenge of diagnosing Plasmodium ovale malaria in travellers: report of six clustered cases in French soldiers returning from West Africa. Malar J. 2010;9:358.

3. Collins WE, Jeffery GM. Plasmodium ovale: parasite and disease. Clin Microbiol Rev. 2005;18(3):570-81.

4. Mueller I, Zimmerman PA, Reeder JC. Plasmodium malariae and Plasmodium ovale-the "bashful" malaria parasites. Trends Parasitol. 2007:23 (6):278-83.

5. Sutherland CJ, Tanomsing N, Nolder D, Oguike M, Jennison C, Pukrittayakamee $S$, et al. Two nonrecombining sympatric forms of the human malaria parasite Plasmodium ovale occur globally. J Infect Dis. 2010;201(10):1544-50.

6. Meneses B, Blair S. Malaria por Plasmodium ovale. Acta Med Colomb. 1995;20(6):288-91.

7. Velázquez A, Álvarez F, Zavala C. Paludismo. Reporte de un caso y revisión de la literatura. Med Sur. 2006;13(3):129-35.

8. Limongi JE, Costa DC, Carvalho LH, Lopes IS, Silva AA, Ferreira MS. Plasmodium ovale malaria in Brazil: report of an imported case with a prolonged incubation period. J Infect Dev Ctries. 2014;8(4):554-7.

9. Arevalo-Herrera M, Quiñones ML, Guerra C, Céspedes N, Giron S, Ahumada $M$, et al. Malaria in selected non-Amazonian countries of Latin America. Acta Trop. 2012;121(3):303-14.

10. Dirección General de Servicios de Salud. División de Malaria de Guatemala. Memoria Anual 1977. Guatemala: Dirección General de Servicios de Salud. División de Malaria de Guatemala; 1978.

11. World Health Organization. World malaria report 2013. Geneva: World Health Organization; 2013.

12. Galappaththy GN, Fernando SD, Abeyasinghe RR. Imported malaria: a possible threat to the elimination of malaria from Sri Lanka? Trop Med Int Health. 2013;18(6):761-8.

13. Juliao PC, Sosa S, Gonzalez LD, Padilla N, Ortiz L, Goldman I, et al. Importation of chloroquine-resistant Plasmodium falciparum by Guatemalan peacekeepers returning from the Democratic Republic of the Congo. Malar J. 2013;12(1):344

14. Patel JC, Taylor SM, Juliao PC, Parobek CM, Janko M, Gonzalez LD, et al. Genetic evidence of importation of drug-resistant plasmodium falciparum to Guatemala from the democratic republic of the Congo. Emerg Infect Dis. 2014;20(6):932-40.

15. Ministerio de Salud Pública y Asistencia Social de Guatemala. Normas de Atención en Salud Integral para el Primero y Segundo Nivel, 2010. Guatemala: Ministerio de Salud Pública y Asistencia Social de Guatemala; 2010.

16. Mangold KA, Manson RU, Koay ES, Stephens L, Regner M, Thomson Jr RB, et al. Real-time PCR for detection and identification of Plasmodium spp. J Clin Microbiol. 2005;43(5):2435-40. doi:10.1128/jcm. 43.5.2435-2440.2005.

17. Snounou G, Viriyakosol S, Zhu XP, Jarra W, Pinheiro $L$, do Rosario VE, et al. High sensitivity of detection of human malaria parasites by the use of nested polymerase chain reaction. Mol Biochem Parasitol. 1993;61(2):315-20.

18. Oguike MC, Betson M, Burke M, Nolder D, Stothard JR, Kleinschmidt I, et al. Plasmodium ovale curtisi and Plasmodium ovale wallikeri circulate simultaneously in African communities. Int J Parasitol. 2011;41(6):677-83. 
19. Shaha DP, Pacha LA, Garges EC, Scoville SL, Mancuso JD. Confirmed malaria cases among Active Component U.S. Army Personnel, January-September 2012. MSMR. 2013;20(1):6-9.

20. Lim YA, Mahmud R, Chew CH, T T, Chua KH. Plasmodium ovale infection in Malaysia: first imported case. Malar J. 2010;9:272.

21. Obare P, Ogutu B, Adams M, Odera JS, Lilley K, Dosoo D, et al.

Misclassification of Plasmodium infections by conventional microscopy and the impact of remedial training on the proficiency of laboratory technicians in species identification. Malar J. 2013;12:113.

22. World Health Organization. Global report on antimalarial drug efficacy and drug resistance: 2000-2010. Geneva: World Health Organization; 2010.

23. Matisz CE, Naidu P, Shokoples SE, Grice D, Krinke V, Brown SZ, et al.

Post-arrival screening for malaria in asymptomatic refugees using real-time PCR. Am J Trop Med Hyg. 2011;84(1):161-5.

24. Hill DR, Baird JK, Parise ME, Lewis LS, Ryan ET, Magill AJ. Primaquine: report from CDC expert meeting on malaria chemoprophylaxis I. Am J Trop Med Hyg. 2006;75(3):402-15

\section{Submit your next manuscript to BioMed Central and take full advantage of:}

- Convenient online submission

- Thorough peer review

- No space constraints or color figure charges

- Immediate publication on acceptance

- Inclusion in PubMed, CAS, Scopus and Google Scholar

- Research which is freely available for redistribution 